Vol 2 No 2 Desember 2021

Jurnal AlphaEuclidEdu

Received: 08/09/2021; Resived: 13/10/2021; Accepted: 30/12/2021

\title{
ANALISIS GAYA BELAJAR VISUAL DITINJAU DARI KEMAMPUAN PEMECAHAN MASALAH SISTEM PERSAMAAN LINEAR DUA VARIABEL
}

\author{
Aribah Errina, Mohamamad Rif'at, Silvia Sayu \\ Program Studi Pendidiikan Matematika FKIP Untan Pontianak \\ Mahasiswa: errinaaribah@ gmail.com
}

\begin{abstract}
This review means to depict the investigation of visual learning styles as far as critical thinking capacity of understudies' two-variable direct condition framework at MTS Negeri 3 Mempawah. The examination strategy utilized is enlightening subjective as contextual analyses. The subjects in this study were class VIII students at MTS Negeri 3 Mempawah. The number of students who were used as research subjects were 38 students who had studied the material for a two-variable system of linear equations. In this study, six students were selected consisting of two students who had SPLDV Problem Solving Ability in terms of high, medium, low learning styles. The object of this exploration is Visual Learning Style as far as Critical thinking Capacity. In light of the aftereffects of information examination, meetings and conversation, it can be concluded that Analysis of Visual Learning Styles Judging from the SPLDV Problem-Solving Ability of MT.S Negeri 3 Mempawah Students" shows that students' problem-solving abilities are relatively balanced with learning styles. As a rule, understudies who have high numerical critical thinking capacities have great visual learning styles, understudies with moderate critical thinking capacities have great visual learning styles, understudies with low numerical critical thinking capacities have great visual learning styles.
\end{abstract}

Keywords: Critical Thinking, Two Variable Direct Condition System, Visual Learning Style

\section{Pendahuluan}

Menurut Gagne dan Briggs (1988:182) hakikat pembelajaran secara umum adalah serangkaian latihan yang dimaksudkan untuk memberdayakan sistem pembelajaran agar terjadi. Pembelajaran menyarankan setiap tindakan yang dimaksudkan untuk membantu orang memperoleh kemampuan tertentu. Pembelajaran dapat diartikan sebagai suatu siklus yang dicari agar siswa dapat meningkatkan kapasitas terpendamnya, baik intelektual, penuh perasaan maupun psikomotorik dengan sukses dan produktif untuk mencapai perubahan tingkah laku yang normal. Pembelajaran di sekolah memiliki empat hal yang harus dipikirkan, yaitu penataan, pelaksanaan, penilaian dan pengawasan. Latihan pembelajaran tidak hanya berpusat pada upaya untuk memperoleh informasi sebanyak mungkin yang dapat diharapkan secara wajar, tetapi juga bagaimana memanfaatkan semua informasi yang diperoleh untuk mengelola keadaan baru atau menangani masalah luar biasa yang terkait dengan bidang studi yang diteliti. Matematika adalah salah satu ilmu dasar yang memainkan peran penting dalam kehidupan sehari-hari. Oleh karena itu, sejumlah besar energi untuk mengejar soal harus secara konsisten memikirkan peningkatan matematika, penerapan dan penggunaan matematika untuk mengatasi masalah-masalah biasa. Salah satu standar kapasitas numerik adalah menangani masalah numerik.

Kapasitas berpikir kritis numerik adalah bagian penting dari belajar matematika. Namun, sebenarnya kemampuan berpikir kritis numerik siswa sekolah menengah masih 
Vol 2 No 2 Desember 2021

Jurnal AlphaEuclidEdu

Received: 08/09/2021; Resived: 13/10/2021; Accepted: 30/12/2021

sangat rendah. Hal ini dapat dilihat dari konsekuensi ikhtisar PISA dan TIMSS. Konsekuensi dari tinjauan PISA untuk kapasitas numerik secara konsisten, Indonesia secara konsisten mendapat skor di bawah normal dunia dan posisi di bawahnya. Dalam penelitian tersebut, salah satu bagian dari kapasitas intelektual yang dievaluasi adalah kapasitas berpikir kritis numerik. Konsekuensi dari studi PISA 2015, Indonesia berada di posisi 63 dari 70 negara peserta dengan skor normal 386 sedangkan skor normal global 490 (OECD, 2016). Hasil studi TIMMS sangat sedikit tidak sama dengan hasil PISA. Pada tahun 2015 Indonesia menempati posisi ke-45 dari 50 negara dengan skor 397. Artinya, kondisi Indonesia dalam setiap investasinya selalu mendapat skor di bawah batas normal. Mahasiswa yang mengikuti PISA dan delegasi TIMSS dari Indonesia merupakan mahasiswa pilihan terbaik di Indonesia. Dari hasil review, cenderung terlihat bahwa efek samping dari mahasiswa terbaik masih rendah, belum lagi mahasiswa standar lainnya.

Berpikir kritis pada dasarnya adalah suatu usaha untuk menemukan jalan keluar dari suatu kesulitan untuk mencapai suatu tujuan yang tidak dapat dicapai dengan cepat (Polya, 1973); (Teresa et al., 2020). Sesuai dengan itu berpikir kritis adalah interaksi yang dilakukan oleh seorang individu untuk mengurusi masalah yang dihadapinya sampai masalah tersebut pada titik ini bukan masalah bagi individu. Ini berarti bahwa sesuatu adalah masalah bagi seseorang, pada saat yang berbeda itu bukan masalah bagi orang yang bersangkutan. Mengingat persepsi peneliti selama Praktek Pengalaman Lapangan (PPL) dan pertemuan dengan pengajar matematika yang telah dilakukan di MTs Negeri 3 Mempawah tergantung pada hasil yang diperoleh dalam ukuran pembelajaran matematika, masih banyak siswa yang mengalami masalah yang menangani masalah numerik. Hal ini terlihat dari konsekuensi ulangan harian siswa pada materi sebelumnya, khususnya Sistem Persamaan Dua Variabel, yang menunjukkan bahwa dari 64 siswa, 47 siswa atau 73,4\% siswa tidak memenuhi Kriteria Ketuntasan Minimal (KKM). Kriteria nilai tersebut biasanya dimanfaatkan oleh pendidik matematika untuk mengetahui siswa lulus atau tidak nya dalam pencapaian hasil belajar dengan nilai yang ditetapkan 75 .

Menurut Peker (2009: 335); (Halimah et al., 2018), berbagai penelitian telah menunjukkan bahwa secara dominan siswa memiliki kesulitan dalam belajar matematika serta lemah dalam prestasi bidang matematika seperti kemampuan pemecahan masalah yang tentunya membutuhkan penalaran. Seperti yang ditunjukkan oleh Peker (2009:335), penelitian yang berbeda menunjukkan bahwa siswa secara transendental mengalami masalah dalam belajar matematika dan lemah dalam pencapaian dalam aritmatika, misalnya, kemampuan berpikir kritis yang jelas membutuhkan pemikiran. Ada banyak karakteristik siswa yang mempengaruhi hal tersebut seperti usia, jenis kelamin, motivasi, gaya belajar, perkembangan kognitif, perkembangan sosio-emosional, perkembangan moral dan karakter. Namum pada penelitian ini peneliti lebih terfokus pada gaya belajar siswa. Gaya belajar dapat dikelompokkan menjadi tiga yaitu gaya belajar visual, gaya belajar mendengar, dan gaya belajar sensasi. 1) gaya belajar visual menjelaskan bahwa seseorang dengan gaya belajar ini pada awalnya harus melihat bukti dan kemudian memiliki pilihan untuk mempercayainya, misalnya melalui representasi, gambar, rekaman, dan lain-lain; 2) Selain itu, gaya belajar mendengar adalah gaya belajar yang bergantung pada pendengaran untuk memiliki pilihan untuk memahami dan mempercayainya; 3) Gaya belajar sensasional adalah gaya belajar dimana seorang individu menggunakan bagian-bagian tertentu dari tubuhnya sebagai perangkat belajar yang ideal (DePotter dan Hernacki, 2009: 116); (Armiyansyah et al., 2021). 
Vol 2 No 2 Desember 2021

Jurnal AlphaEuclidEdu

Received: 08/09/2021; Resived: 13/10/2021; Accepted: 30/12/2021

Penelitian sebelumnya tentang kapasitas berpikir kritis dan gaya belajar, khususnya akibat dari ujian Dewi Mentari (2019) yang menyimpulkan bahwa subjek diverger, konvergen, akomodator, dan asimilator menunjukkan berbagai kapasitas dalam sistem berpikir, khususnya subjek konvergen dan asimilator keduanya menggunakan contoh yang sama. juga, koneksi untuk mengembangkan tebakan atau tebakan dan spekulasi terkait dengan informasi yang dimiliki, namun subjek asimilator lebih metodis. Berangkat dari landasan yang digambarkan di atas, maka penulis tertarik untuk mengarahkan sebuah kajian yang berjudul "Analisis Gaya Belajar Visual Ditinjau Dari Kemampuan Pemecahan Masalah Sistem Persamaan Linier Dua Variabel Siswa di MTS Negeri 3 Mempawah".

\section{Metode Penelitian}

Eksplorasi semacam ini adalah penelitiank kualitatif. Untuk mencapai tujuan penelitian, peneliti mengumpulkan informasi yang diperoleh, kemudian menyusun eksplorasi yang menghasilkan struktur cerita yang ditunjukkan dengan apa yang terjadi selama pemeriksaan di lapangan (Nawawi, 2015: 67). Oleh karena itu, strategi yang akan digunakan dalam eksplorasi ini adalah metode deskriptif. Jenis eksplorasi yang digunakan dalam tinjauan ini adalah investigasi kontekstual. Subjek dalam review ini adalah siswa kelas VIII di MTS Negeri 3 Mempawah. Jumlah siswa yang dijadikan sebagai subjek ujian adalah 38 siswa yang telah membaca materi sistem persamaan dua variabel.

Dalam tinjauan ini dipilih enam mahasiswa yang terdiri dari dua mahasiswa yang memiliki Kapasitas Berpikir Kritis SPLDV tinggi Dilihat dari Gaya Belajarnya, dua mahasiswa yang memiliki Kapasitas Berpikir Kritis sedang, dan dua mahasiswa yang memiliki Kapasitas Berpikir Kritis rendah. Alasan ilmuwan memilih enam siswa sebagai subjek ujian adalah agar analis dapat menyelam lebih jauh ke dalam Gaya Belajar Visual sejauh kemampuan berpikir Kritis SPLDV siswa.

Objek penelitian ini adalah Pengambilan Visual dalam Gaya Memutuskan Kemampuan Berpikir Kritis siswa SPLDV tinggi, sedang dan rendah. prosedur yang digunakan untuk mengumpulkan informasi adalah strategi korespondensi yang menyimpang, metode pengujian yang disusun, dan strategi korespondensi langsung. Strategi korespondensi backhanded adalah sebagai polling gaya belajar ke atas dari 15 pernyataan yang akan diberikan sebelum siswa mengerjakan soal kemampuan berpikir kritis SPLDV. Strategi tes yang disusun adalah melalui pemberian kemampuan berpikir kritis. Strategi korespondensi langsung adalah metode pengumpulan informasi melalui pertanyaan yang disampaikan secara lisan. Dalam ulasan ini, strategi korespondensi langsung sebagai pertemuan. Instrumen Ujian seperti Poll Gaya Belajar, Soal Tes Kapasitas Berpikir Kritis, dan rapat.

\section{Tahap Persiapan}

Sarana yang ditempuh pada tahap persiapan antara lain: (1) Mengarahkan pra penelitian pada siswa kelas VIII di MTS Negeri 3 Mempawah. (2) Menyusun rencana proposisi pemeriksaan yang mencakup presentasi, audit hipotetis, teknik penelitian, dan rencana instrumen eksplorasi. (3) Mengembangkan instrumen eksplorasi seperti survei gaya belajar siswa, soal tes kemampuan berpikir kritis, dan aturan rapat. (4) Lokakarya 
Vol 2 No 2 Desember 2021

Jurnal AlphaEuclidEdu

Received: 08/09/2021; Resived: 13/10/2021; Accepted: 30/12/2021

rencana eksplorasi. (5) Ubah konfigurasi pemeriksaan tergantung pada efek samping bengkel. (6) Melakukan persetujuan isi pada instrumen pemeriksaan. (7) Memeriksa dan mempertimbangkan kembali instrumen penelitian tergantung pada hasil persetujuan. (8) Mengarahkan uji coba instrumen survei gaya belajar siswa dan inkuiri tes kemampuan berpikir kritis kepada 35 siswa kelas VIII di MTS Negeri 3 Mempawah. (9) Menyelidiki dan memodifikasi instrumen penelitian tergantung pada konsekuensi pendahuluan. (10) Menyebutkan kewenangan memimpin penelitian di MTS Negeri 3 Mempawah.

\section{Tahap Pelaksanaan}

Langkah-langkah yang dilakukan pada tahap pelaksanaan antara lain: (1) Pemberian survey gaya belajar kepada 35 siswa kelas VIII MTS Negeri 3 Mempawah. (2) Merinci konsekuensi dari polling gaya belajar siswa dan mengklasifikasikan survei gaya belajar siswa. (3) Pemberian soal tes kemampuan berpikir kritis SPLDV. (4) Menyelidiki efek samping dari jawaban tes kemampuan berpikir kritis SPLDV siswa. (5) Pertemuan langsung. (6) Mengarahkan pemeriksaan hasil rapat. (7) Menggambarkan informasi eksplorasi. (8) Mencapai kesimpulan untuk menjawab rencana masalah.

\section{Tahap Akhir Penelitian}

Tahap terakhir adalah mengumpulkan laporan pemeriksaan.

\section{Hasil Penelitian dan Pembahasan}

Instrumen yang digunakan dalam pengumpulan informasi adalah polling gaya belajar, tes kemampuan berpikir kritis, dan pertemuan. Jajak pendapat tersebut terdiri dari 15 hal proklamasi yang terdiri dari tiga penanda survei gaya belajar, khususnya visual, pendengaran, dan sensasi. Efek samping dari penyelidikan survei gaya belajar membawa pengumpulan gaya belajar. Tes kapasitas berpikir kritis adalah sebagai penggambaran yang terdiri dari empat pertanyaan dimana setiap pertanyaan mengandung setiap penanda kapasitas berpikir kritis. Dalam aksi pertemuan tersebut, ahli mengungkap lebih banyak tentang kemampuan berpikir kritis yang tidak ditemukan dalam hasil tes yang disusun. Penyelidikan informasi dilakukan secara subjektif di mana analis memperkenalkan informasi sebagai akun, tabel, dan garis besar.

\section{Analisis data angket gaya belajar}

Setelah klasifikasi dilakukan seperti yang ada pada lampiran, siswa dikelompokan dalam msing-masing tipe gaya belajar. Konsekuensi dari koleksi siswa tergantung pada efek samping dari survei gaya belajar dapat ditemukan pada tabel di bawah ini.

Tabel 1. Pengelompokan Siswa Berdasarkan Hasil Angket Gaya Belajar

\begin{tabular}{|c|c|c|c|c|c|c|}
\hline \multirow{2}{*}{ No. } & \multirow{2}{*}{ Kode siswa } & \multicolumn{3}{|c|}{ Skor } & \multirow{2}{*}{ Gaya Belajar } & \multirow{2}{*}{ Keterangan } \\
\cline { 3 - 5 } & V & A & K & & Jawaban dominan visual \\
\hline 1 & KSH & 15 & 12 & 10 & Visual & Jawaban dominan visual \\
\hline 2 & RSA & 16 & 8 & 9 & Visual & Jawaban dominan visual \\
\hline 3 & APN & 15 & 10 & 11 & Visual & Jawaban dominan visual \\
\hline 4 & RMD & 17 & 10 & 11 & Visual & Jawaban dominan visual \\
\hline 5 & WN & 16 & 12 & 10 & Visual & Jawaban dominan visual \\
\hline 6 & AKR & 17 & 9 & 11 & Visual & Jawn visual \\
\hline 7 & RH & 17 & 9 & 8 & Visual & Jawaban dominan venann \\
\hline
\end{tabular}


Vol 2 No 2 Desember 2021

Jurnal AlphaEuclidEdu

Received: 08/09/2021; Resived: 13/10/2021; Accepted: 30/12/2021

\begin{tabular}{|c|c|c|c|c|c|c|}
\hline 8 & QA & 16 & 9 & 8 & Visual & Jawaban dominan visual \\
\hline 9 & NN & 15 & 8 & 11 & Visual & Jawaban dominan visual \\
\hline 10 & EGA & 16 & 9 & 8 & Visual & Jawaban dominan visual \\
\hline
\end{tabular}

Berdasarkan analisis data yang sudah dilakukan pada hasil pengisian kuesioner angket gaya belajar 10 siswa kelas VIII yang menjadi subjek di MTS Negeri 3 Mempawah cenderung gaya belajar visual.

\section{Analisis Data Kemampuan Pemecahan Masalah}

Setelah siswa koleksi keyakinan melalui efek dari jajak pendapat gaya belajar yang diberikan kepada siswa, siswa diberikan tes kemampuan berpikir kritis numerik. Kapasitas berpikir kritis numerik yang terdiri dari empat pertanyaan penggambaran dengan empat petunjuk, khususnya: (1) Memahami Masalah; (2) Membuat Pengaturan Finishing; dan (3) Melaksanakan Pengaturan; (4) Meninjau Balasan. Efek samping dari tes kapasitas berpikir kritis numerik diperkenalkan pada Tabel di bawah ini.

Tabel 2. Hasil Tes Kemampuan Pemecahan Masalah

\begin{tabular}{|c|c|c|c|c|c|c|c|c|}
\hline \multirow{2}{*}{$+\mathrm{No}$} & \multirow{2}{*}{ Inisial Siswa } & \multicolumn{4}{|c|}{ Butir Soal } & \multirow{2}{*}{ Skor Total } & \multirow{2}{*}{ Persentase } & \multirow{2}{*}{ Kriteria } \\
\hline & & 1 & 2 & 3 & 4 & & & \\
\hline 1 & RMD & 4 & 4 & 4 & 3 & 15 & 93,75 & Tinggi \\
\hline 2 & RSA & 4 & 3 & 3 & 3 & 13 & 81,25 & Tinggi \\
\hline 3 & $\mathrm{WN}$ & 3 & 4 & 3 & 3 & 13 & 81,25 & Tinggi \\
\hline 4 & KSH & 3 & 3 & 3 & 2 & 11 & 68,75 & Sedang \\
\hline 5 & $\mathrm{RH}$ & 3 & 3 & 3 & 2 & 11 & 68,75 & Sedang \\
\hline 6 & NN & 3 & 3 & 3 & 2 & 11 & 68,75 & Sedang \\
\hline 7 & APN & 3 & 3 & 2 & 2 & 10 & 62,5 & Sedang \\
\hline 8 & AKR & 3 & 3 & 2 & 2 & 10 & 62,5 & Sedang \\
\hline 9 & QA & 3 & 3 & 2 & 1 & 9 & 56,25 & Rendah \\
\hline 10 & EGA & 2 & 2 & 2 & 2 & 8 & 50 & Rendah \\
\hline
\end{tabular}

Berdasarkan hasil tes kemampuan berpikir kritis numerik siswa yang disajikan pada Tabel 2, pada umumnya setelah skor per angka dijumlahkan, siswa yang memiliki kemampuan berpikir kritis numerik tinggi adalah 3 siswa atau 30\%, siswa yang memiliki kemampuan berpikir kritis numerik sedang adalah 5 siswa atau setengahnya, dan siswa yang memiliki kemampuan berpikir kritis numerik rendah adalah 2 siswa atau $20 \%$.

Analisis Data Tes Kemampuan Pemecahan Masalah Matematis Ditinjau dari Angket Gaya Belajar

Penelusuran akibat tes kemampuan berpikir kritis numerik untuk melihat kemampuan berpikir kritis numerik siswa pada materi sistem persamaan linear dua variabel sejauh gaya belajar disajikan pada tabel.

Tabel 3. Hasil Tes Kemampuan Pemecahan Masalah Matematis dan Gaya Belajar Kelas VIII Mts.N 3 Mempawah

\begin{tabular}{|l|l|l|l|l|l|l|}
\hline No. & & Butir Soal & Skor Total & Persentase & Kriteria \\
\hline
\end{tabular}


Vol 2 No 2 Desember 2021

Jurnal AlphaEuclidEdu

Received: 08/09/2021; Resived: 13/10/2021; Accepted: 30/12/2021

\begin{tabular}{|c|c|c|c|c|c|c|c|c|c|}
\hline & $\begin{array}{c}\text { Kode } \\
\text { siswa }\end{array}$ & $\begin{array}{c}\text { Skor } \\
\text { Visual }\end{array}$ & 1 & 2 & 3 & 4 & & & \\
\hline 1 & RSA & 80 & 4 & 3 & 3 & 3 & 13 & 81,25 & Tinggi \\
\hline 2 & RMD & 85 & 4 & 4 & 4 & 3 & 15 & 93,75 & Tinggi \\
\hline 3 & WN & 80 & 3 & 4 & 3 & 3 & 13 & 81,25 & Tinggi \\
\hline 4 & KSH & 75 & 3 & 3 & 3 & 2 & 11 & 68,75 & sedang \\
\hline 5 & APN & 75 & 3 & 3 & 2 & 2 & 10 & 62,5 & sedang \\
\hline 6 & AKR & 85 & 3 & 3 & 2 & 2 & 10 & 62,5 & sedang \\
\hline 7 & RH & 85 & 3 & 3 & 3 & 2 & 11 & 68,75 & sedang \\
\hline 8 & NN & 75 & 3 & 3 & 3 & 2 & 11 & 68,75 & sedang \\
\hline 9 & QA & 80 & 3 & 3 & 2 & 1 & 9 & 56,25 & Rendah \\
\hline 10 & EGA & 80 & 2 & 2 & 2 & 2 & 8 & 50 & Rendah \\
\hline
\end{tabular}

Berdasarkan Tabel 3 diperoleh informasi atau data bahwa terdapat tiga siswa yang tergolong memiliki gaya belajar visual dengan tiga siswa memiliki kemampuan berpikir kritis numerik tinggi, lima siswa memiliki kemampuan berpikir kritis numerik sedang, dan dua siswa memiliki kemampuan berpikir kritis numerik rendah.

\section{Pembahasan}

Mengingat efek samping dari ujian eksplorasi survei gaya belajar, tes kemampuan berpikir kritis numerik, dan pertemuan, cenderung terlihat bahwa kapasitas gaya belajar setiap siswa bergeser. Selain itu, siswa yang memiliki gaya belajar yang sama juga dapat memiliki kemampuan berpikir kritis yang berbeda. Hal ini sesuai dengan penilaian Bandler dan Processor (dalam DePorter 2002: 85) yang menyatakan bahwa hampir setiap orang pada umumnya akan membuat mereka belajar gaya yang berperan dalam mengambil, menyiapkan, dan berkorespondensi.

Pharsing (2007: 85). Diungkapkan bahwa ketika siswa menggunakan gaya belajar yang sesuai dengan mereka dalam sistem pembelajaran akan sangat mempengaruhi mereka, memberikan solusi yang nyaman, tetapi juga pada akhirnya akan menjadi obat dalam jangka panjang bagi siswa untuk mendominasi di sekolah. Sejalan dengan itu, pengajar perlu mengenali ragam gaya belajar yang digerakkan oleh siswa seperti yang diungkapkan oleh Martinez-pons (2001: 7) dalam penelitian otak mendidik dan belajar bahwa dalam belajar penting bagi seorang guru untuk melakukan periode yang mendasari pembelajaran, khususnya tahap di mana seorang guru mengetahui dan memahami pengaturan dasar yang dimiliki siswa. Aturan dasar yang diingat untuk tahap ini adalah mengetahui bagaimana jenis gaya belajar siswa sehingga sangat baik dapat dipertimbangkan dan berkontribusi bagi instruktur untuk dapat merancang pembelajaran dengan tujuan untuk lebih mengembangkan kemampuan berpikir kritis numerik siswa.

Dalam keadaan hasil belajar ini, siswa lebih percaya pada masalah aplikasi numerik, termasuk belajar melalui materi kerangka kondisi langsung dua variabel. Hal ini juga menegaskan hipotesis pembelajaran signifikan, khususnya matematika yang dipelajari disesuaikan dan dikaitkan dengan informasi yang dimiliki siswa saat ini dan menjadi signifikan jika dikaitkan dengan gaya belajar visual. Setelah merinci informasi tes jajak pendapat dan tes kapasitas berpikir kritis numerik, mereka terus mengarahkan pertemuan. Alasan dan kapasitas pertemuan dalam penelitian adalah untuk memperoleh 
Vol 2 No 2 Desember 2021

Jurnal AlphaEuclidEdu

Received: 08/09/2021; Resived: 13/10/2021; Accepted: 30/12/2021

data secara lugas untuk memperjelas sesuatu yang spesifik atau keadaan dan kondisi. untuk menyelesaikan dan memperoleh informasi yang tepat untuk menggambarkan hasil informasi yang tepat. Selanjutnya pembahasan lebih mendalam tentang kapasitas berpikir kritis numerik sejauh gaya belajar pada materi sistem persamaan linear dua variabel di MTs.N 3 Mempawah.

\section{Kemampuan pemecahan masalah matematis bagi siswa yang memiliki gaya belajar visual tinggi, sedang dan rendah}

Seorang siswa yang menjadi subjek ujian dari kelompok gaya belajar visual pada penanda pemahaman masalah memperoleh data bahwa ada skor yang dapat diterima dengan klasifikasi tinggi. Siswa-siswa ini memperoleh pencapaian kemampuan berpikir kritis numerik sebesar 93,75\% pada kelas tinggi, 68,75\% pada klasifikasi sedang, dan setengahnya pada kelas rendah.

\section{Kesimpulan dan Saran \\ Kesimpulan}

Berdasarkan hasil penelusuran informasi, pertemuan dan percakapan, maka cenderung diduga bahwa "Analisis Gaya Belajar Visual Ditinjau dari Kemampuan Pemecahan Masalah SPLDV Siswa MT.S Negeri 3 Mempawah" menunjukkan bahwa kemampuan berpikir kritis siswa sangat rendah. umumnya diimbangi dengan gaya belajar. Pada umumnya siswa yang memiliki kemampuan berpikir kritis numerik tinggi memiliki gaya belajar visual yang baik, sedangkan siswa dengan kemampuan berpikir kritis sedang memiliki gaya belajar visual yang baik, serta siswa dengan kemampuan berpikir kritis numerik yang rendah memiliki gaya belajar visual yang baik.

\section{Saran}

Gagasan yang perlu diteruskan oleh para ilmuwan tergantung pada konsekuensi dari tinjauan ini yaitu pendidik matematika diandalkan untuk memikirkan akibat dari ulasan ini dan mengisinya sebagai informasi atau referensi dalam pembelajaran aritmatika, khususnya dalam mengembangkan lebih lanjut kemampuan berpikir kritis numerik siswa pada materi kerangka kondisi langsung dua variabel. Hal ini dapat diketahui dalam satu cara seperti memberikan pertanyaan non-rutin kepada siswa atau mempersiapkan siswa untuk pertanyaan konfigurasi (presentasi masalah). Siswa diandalkan untuk bekerja pada wawasan dan pemahaman ide-ide mereka seperti pelatihan pertanyaan non-rutin diidentifikasi dengan pengaturan kondisi langsung dari dua faktor untuk lebih mengembangkan kemampuan berpikir kritis.

\section{Referensi}

DePorter, Bobbi dan Hernacki, Mike. 2009. Quantum Learning: Membiasakan Belajar Nyaman dan Menyenangkan. Bandung: Kaifa Learning.

Gagne dan Briggs. 1979. Pengertian Pembelajaran. Diakses melalui link http://www.scribd.com/doc/50015294/13/B-Pengertian pembelajaranmenurutbeberapa-ahli (diakses pada tanggal 10 januari 2021).

Nawawi, Hadari. (2012). Metode Penelitian Bidang Sosial. Yogyakarta: Gajah Mada University Press.

Peker, M. (2009). "Pre-Service Teachers' Teaching Anxiety about Mathematics and Their Learning Styles". Eurasia Journal of Mathematics, Science, \& Technology Eductaion. 5 (4), 335-345. 
Vol 2 No 2 Desember 2021

Jurnal AlphaEuclidEdu

Received: 08/09/2021; Resived: 13/10/2021; Accepted: 30/12/2021

Polya. G. (1973) How to Solve It: A New Aspect of Mathematical Method (Second ed). New Jersey: Princeton University Press. Tersedia: https://notendur.hi.is/hei2/teaching/Polya HowToSolveIt.pdf (20 Januari 2021).

Prashing, B (2007). The Power Of Learning Stayles. Memacu anak melejitkan prestasi dengan mengenali gaya belajarnya. Terjemahan nina fauziah. The Power Of Diversity New Ways Of Learning and Teaching Through Learning Styles. 1998. Bandung: kaifa.

Siswono,Tatag Yuli Eko. 2008. Model Pembelajaran Matematika Berbasis Pengajuan Masalah dan Pemecahan Masalah untuk Meningkatkan Kemampuan Berpikir Kreatif. Surabaya: Unesa University Press.

Armiyansyah, Sugiatno, \& Bistari. (2021). Hambatan siswa dalam belajar matematika dikaji dari kepercayaan matematis 1 1,2,3. Jurnal AlphaEuclidEdu, 2(1), 40-50.

Halimah, M., Solfarina, \& Langitasari, I. (2018). Visual imagery strategy as effort to acquire comprehension. Jurnal Profesi Keguruan, 5(1), 135-141.

Teresa, H., Zubaidah, Z., \& Nursangaji, A. (2020). Kemampuan Menyelesaikan Soal Pisa Pada Konten Change and Relationship. Jurnal AlphaEuclidEdu, 1(2), 60. https://doi.org/10.26418/ja.v1i2.42879 